\title{
Long-term outcome in relationship to neonatal transfusion volume in extremely premature infants: a comparative cohort study
}

\author{
Jeannette S von Lindern ${ }^{1,2^{*}+}$, Chantal M Khodabux ${ }^{2,3{ }^{\dagger}}$, Karien EA Hack ${ }^{4}$, Ingrid $\mathrm{C}$ van Haastert ${ }^{5}$, \\ Corine Koopman-Esseboom ${ }^{5}$, Paul HT van Zwieten ${ }^{7}$, Anneke Brand ${ }^{3,6}$ and Frans J Walther ${ }^{1}$
}

\begin{abstract}
Background: In premature born infants red blood cell (RBC) transfusions have been associated with both beneficial and detrimental sequels. Upon RBC transfusion, improvement in cerebral blood flow and oxygenation have been observed, while a more liberal transfusion policy may be associated with a better developmental outcome. The effect of the transfusion volume on long-term outcome is not known.

Methods: Observational follow-up study of a cohort of extremely premature born infants, treated in 2 neonatal intensive care units using a different transfusion volume (15 ml/kg in Unit A and $20 \mathrm{ml} / \mathrm{kg}$ in Unit B). The primary outcome was a composite of post discharge mortality, neuromotor developmental delay, blindness or deafness, evaluated at a mean corrected age (CA) of 24 months related to the transfusion volume/kg bodyweight administered during the postnatal hospital stay.

Results: Despite the difference in transfusion volume in clinically comparable groups of infants, they received a similar number of transfusions (5.5 \pm 3.2 versus $5.5 \pm 2.3$ respectively in Unit A and B). The total transfused volume in unit $A$ was $79 \pm 47 \mathrm{ml} / \mathrm{kg}$ and $108 \pm 47 \mathrm{ml} / \mathrm{kg}$ in unit $B(p=0.02)$. Total transfused RBC volume per $\mathrm{kg}$ bodyweight was not an independent predictor of the composite outcome ( $p=0.96$, OR 1.0 (Cl 0.9-1.1).

Conclusion: There was no relationship between the composite outcome at 24 months CA and transfusion volume received during the post natal hospital stay. As there was no clinical advantage of the higher transfusion volume, a more restrictive volume will reduce total transfusion volume and donor exposure. Future research on the optimal transfusion volume per event to extreme preterm infants should include larger, prospective studies with a longer follow-up period through to childhood or even adolescence.
\end{abstract}

\section{Background}

There is ongoing uncertainty whether transfusion of red blood cells (RBC) in the neonatal period influences the clinical outcome and development of premature infants. In the international literature there is discussion about the optimal transfusion volume and trigger [1].

We previously published a study comparing two transfusion dosages of the same RBC product in two Dutch tertiary care neonatal units (NICUs) using the same transfusion trigger protocols [2]. No difference in short-

\footnotetext{
* Correspondence: j.s.von_lindern@lumc.nl

† Contributed equally

'Division of Neonatology J6-S, Department of Pediatrics, Leiden University

Medical Center, PO BOX 9600, 2300RC Leiden, the Netherlands

Full list of author information is available at the end of the article
}

term outcome and mortality was observed in extremely and very preterm infants when a dose of $15 \mathrm{ml} / \mathrm{kg}$ had been administered compared to a volume of $20 \mathrm{ml} / \mathrm{kg}$ bodyweight.

Little is known about the long-term follow-up of extremely premature infants after RBC transfusion. Only a few randomized trials have been published on longterm outcome in premature infants with difference in transfusion practice $[3,4]$. However, these were studies (the PINT trial and the Iowa trial) comparing liberal and restrictive transfusion triggers, exposing the infants in the restrictive group to the possible risks of a low hemoglobin level $[5,6]$. In sequel to our study on shortterm outcome we also wanted to compare long-term

\section{Biomed Central}


outcome in the same group of extremely premature infants treated with different transfusion volumes but with otherwise comparable transfusion triggers and transfusion products.

In our follow-up study we evaluated post discharge mortality, neuromotor developmental outcome and disabilities in a cohort of extremely premature born infants born before 28 gestational weeks in two Dutch tertiary NICUs.

\section{Methods}

\section{Ethics}

In the Netherlands no ethical approval is required for this type of research as no new intervention or treatment is studied. All collected data were anonymous.

\section{Study population}

This is a follow-up study of a cohort of extremely premature infants born before 28 gestational weeks that participated in a previous study on transfusion practice and short-term outcome in two Dutch NICUs. All infants were transfused using the same transfusion triggers and with a similar RBC blood product with only a different volume per event, i.e. 15 and $20 \mathrm{ml} / \mathrm{kg}$ bodyweight. The study design was previously described [2]. The primary outcome measure was a composite of post discharge mortality, neuromotor developmental outcome and disabilities.

\section{Transfusion guideline and product}

All infants were transfused according to the Dutch consensus for blood transfusion 2004 [7]. The recommended transfusion triggers vary with postnatal age, degree of illness and need for respiratory support:

- $\mathrm{Hb}<8 \mathrm{mmol} / \mathrm{l}(13 \mathrm{~g} / \mathrm{dl})$ (hematocrit (Hct) range $0.38-0.40 \mathrm{l} / \mathrm{l}$ ) capillary (or $<7 \mathrm{mmol} / \mathrm{l}$ arterial $(11 \mathrm{~g} / \mathrm{dl}$ ) (Hct 0.32-0.35 1/1)): the first 24 hours after birth in all infants with clinical symptoms of anemia (tachycardia, supplemental oxygen need, apnoea, bradycardia); in all infants on mechanical ventilation or severely ill.

- $\mathrm{Hb}<7 \mathrm{mmol} / \mathrm{l}(12 \mathrm{~g} / \mathrm{dl})$ (Hct 0.32-0.35 l/l) capillary: reasonably stable infants with cardio-respiratory problems (patent ductus arteriosus, apnoea, bronchopulmonary dysplasia, need for supplemental oxygen).

- $\mathrm{Hb}<6 \mathrm{mmol} / \mathrm{l}(10 \mathrm{~g} / \mathrm{dl})$ (Hct 0.27-0.30 l/l) capillary: stable premature infants with a postnatal age $<4$ weeks.

- $\mathrm{Hb}<4.5 \mathrm{mmol} / \mathrm{l}(7 \mathrm{~g} / \mathrm{dl})(\mathrm{Hct} 0.2-0.23 \mathrm{l} / \mathrm{l})$ capillary: stable infants with a postnatal age $>4$ weeks if there are no signs of anemia (apnoea, tachycardia, poor weight gain, poor feeding). In case of symptomatic anemia, transfusion is recommended at a higher threshold.

Transfusion volume per $\mathrm{kg}$ bodyweight was different between the two hospitals; $15 \mathrm{ml} / \mathrm{kg}$ in Unit A and 20 $\mathrm{ml} / \mathrm{kg}$ in Unit B. This transfusion volume was part of the standard practice in the hospitals and was not chosen for study purposes. The same transfusion product was used in both hospitals. All products consisted of pre-storage filtered RBC stored in additive solution Saline Adenine Glucose Mannitol (SAG-M) (maximum storage time 35 days), with a hematocrit of $0.58 \pm 0.05 \mathrm{l} / \mathrm{l}$. The products were irradiated with 25 Gy less than 24 hours before transfusion.

Preventative measures for anemia of prematurity were not standardised. Erythropoietin was not used in the study units. Iron supplementation was started 6 to 8 weeks after birth if there had been no previous RBC transfusion. After RBC transfusion iron supplementation was postponed for four weeks because of the assumed iron load given with the transfusion.

\section{Data collection and outcome parameters}

Infants with a syndrome or congenital/hereditary anomaly known to cause a neuromotor developmental delay were excluded from analysis. Data on neuromotor developmental outcome, major disabilities (deafness, blindness) and survival at a mean ( \pm SD) corrected age (CA) of $24 \pm 3.4$ months were obtained from each child's outpatient follow-up physician, child-psychologist and/or pediatric physiotherapist, who were all trained in neonatal follow-up. Developmental examination was done in different hospitals. The children were assessed with various instruments depending on the hospital of followup. Instruments used were the Dutch $2^{\text {nd }}$ version of the Bayley Scales of Infant Development-II (BSID-II-NL) [8], the Griffiths Mental Development Scales [9], Alberta Infant Motor Scale (AIMS) [10], and the Hempel [11], Touwen [12], and van Wiechen [13] assessments of neuromotor development. The children were classified as normal, mildly delayed or severely delayed, using the cut-off values of each test, classifying severe neuromotor developmental delay as a score of more than 2 SD below average and mild neuromotor developmental delay as a score 1 to 2 SD below the mean. Non-cooperative children received a general assessment by the physician, pediatric physiotherapist and/or child-psychologist. A parental questionnaire was sent to the parents of the children if follow-up at age 2 years was unknown by any of the previously mentioned professionals.

Our primary outcome was the composite of post discharge mortality, severe hearing or visual impairment, or neuromotor developmental delay at 24 months CA. Visual impairment was defined as $<20 / 200$ of best eye, hearing impairment was defined as the need for a hearing aid or cochlear implant. Neuromotor developmental delay was defined as a score more than 1 SD below the mean. The definition for bronchopulmonary dysplasia (National Institutes of health Consensus, USA) was used 
as described by Ehrenkranz et al [14]. For retinopathy of prematurity the revised international classification was used [15]. Intraventricular hemorrhage was graded according to Volpe [16].

\section{Statistical Analysis}

All variables were analyzed by univariate analysis for continuous variables and Chi-Square or Fishers exact probability test for nominal variables. Backward step wise logistic regression analysis was used for the independent effect of the following factors: hospital (representing transfusion dose and unknown factors), number of RBC transfusions, total transfused RBC volume per $\mathrm{kg}$ bodyweight, gender, gestational age, birth weight, CRIB II score and Apgar-score at 5 minutes. (SPSS 17 Chicago, United States of America). A p-value of less than 0.05 was considered significant.

\section{Results}

Eighty-seven extremely premature infants were included in our earlier cohort study (44 in Unit A, 43 in Unit B). Four infants died the first day of life and were excluded from this follow-up study (1 lung hypoplasia, 1 massive pulmonary hemorrhage, 1 severe perinatal asphyxia and 1 cause unknown). None of these children had received a RBC transfusion. Twelve other patients died in the neonatal period for various reasons; they had all received $\mathrm{RBC}$ transfusions. They were also excluded from follow-up. Seventy-one of the 87 infants $(82 \%)$ left the hospital alive (in total 9 in unit $\mathrm{A}$ and 7 in unit $\mathrm{B}$ died $(\mathrm{p}=0.78)$. There were no deaths after discharge from the units. One other patient was excluded from follow-up analysis because of a severe myopathy. Three children were lost to follow-up in the first year of life; one due to emigration, of the other two (twins) the reason is unknown, leaving 67/70 (96\%) of the eligible infants surviving the post-natal period for neuromotor developmental follow-up.

There were no statistically significant differences when comparing the baseline characteristics of the patients from both units (Table 1). The number of transfusions administered was similar, $5.5 \pm 3.2$ (Unit A) versus $5.5 \pm 2.3$ (Unit B) respectively. As the volume per transfusion event per center differed, the mean total volume transfused in unit A and B was significantly different $(79 \pm 47 \mathrm{ml} / \mathrm{kg}$ versus $108 \pm 47 \mathrm{ml} /$ $\mathrm{kg}(\mathrm{p}=0.02)$ respectively). Neuromotor development was evaluated at a mean $24 \pm 3.4$ months CA. One infant had a severe visual impairment and one child had severe hearing loss. Forty-seven out of 67 (70.1\%) infants showed normal neuromotor development for corrected age. Seventeen infants $(25.4 \%)$ had a mild developmental delay and three infants were severely impaired (4.5\%).
There was no statistically significant difference in the transfused volume for the primary outcome (composite of post discharge mortality, neuromotor developmental delay, blindness or deafness) compared to children with a normal outcome $(105 \pm 52 \mathrm{ml}$ versus $90 \pm 47 \mathrm{ml}$ respectively) ( $\mathrm{p}=0.96$, OR $1.0(0.9-1.1)$. In multivariate analysis none of the tested variables reached statistical significance for an independent association with the composite outcome (Table 2).

\section{Discussion}

Transfusion of RBC has been associated with negative and positive effects on clinical outcome. Our study showed no significant differences between a smaller and a larger transfusion volume regarding a composite outcome of post discharge mortality, neuromotor developmental outcome and disabilities at 2 years CA. This would imply that a smaller transfusion volume rather has advantages (generally limiting donor exposure and costs), than negative effects on neuromotor developmental outcome. It is possible that no effects were seen because the difference in transfusion volume per transfusion event was not large enough. On the other hand, the total transfusion volume $/ \mathrm{kg}$ during the post natal hospital stay was significantly different in the two NICUs. Several studies associated RBC transfusion with the development of retinopathy of prematurity [17-20] and chronic lung disease [21-23]. It is hypothesized that iron overload, caused by multiple RBC transfusions, increases oxidative stress leading to free radical-induced injury to the premature retina and developing lungs $[24,25]$. However, anemia has been associated with negative effects as well and in particular the brain may be susceptible to low hemoglobin levels. Bell et al, in a randomized study, found a statistically significant higher incidence in the number of infants with intracranial hemorrhage grade IV or periventricular leukomalacia when a restrictive transfusion threshold was applied as compared to a more liberal threshold [5]. On the other hand, neither Chen [24] nor Kirpalani (PINT trial) [6] found a statistically significant difference in the occurrence of (severe) intracranial pathology. However, the follow-up study by Whyte et al. of infants included in the PINT trial, suggested that preterm infants treated with a more liberal transfusion regime may have a better developmental outcome [4]. The premature infants included in this multicenter PINT trial were analyzed at 18-21 months CA with regard to mortality, cerebral palsy, severe visual impairment, hearing-loss, a BayleyMental Developmental Index (MDI) score $<70$, and a composite of these variables. Although there was no statistically significant difference in composite outcome ( $45 \%$ in the restrictive and $38 \%$ in the liberal group), the difference in cognitive delay (MDI score <70) 
Table 1 Characteristics of patients per unit included in follow-up study

\begin{tabular}{lllll}
\hline & Total $(\mathbf{n}=\mathbf{6 7})$ & Unit $\mathbf{A}(\mathbf{n}=\mathbf{3 1})$ & Unit $\mathbf{B}$ ( $\mathbf{n}=\mathbf{3 6})$ & $\mathbf{p}$-value \\
\hline Male, $\mathrm{n}$ & $61 \%(41)$ & $74 \%(23)$ & $50 \%(18)$ & 0.05 \\
\hline Gestational age, weeks mean SD & $266 / 7 \pm 4 / 7$ & $266 / 7 \pm 4 / 7$ & $266 / 7 \pm 4 / 7$ & 0.65 \\
\hline Birth weight, grams mean SD & $900 \pm 187$ & $906 \pm 178$ & $895 \pm 197$ & 0.59 \\
\hline AS 5 minutes, median (IQR) & $8(7-9)$ & $8(7-9)$ & $8(7-9)$ & 0.88 \\
\hline IVH $\geq$ grade 3 & $9 \%(6)$ & $13 \%(4)$ & $6 \%(2)$ & 0.40 \\
\hline BPD $\geq$ moderate & $35 \%(23)$ & $29 \%(9)$ & $40 \%(14)$ & 0.35 \\
\hline ROP $\geq$ grade 2 & $12 \%(8)$ & $13 \%(4)$ & $11 \%(4)$ & 1.0 \\
\hline Total number of transfusions, mean SD & $5.5 \pm 2.7$ & $5.5 \pm 3.2$ & $5.5 \pm 2.3$ & 0.98 \\
\hline ML/per kg RBC administered, mean SD & $95 \pm 49$ & $79 \pm 47$ & $108 \pm 47$ & 0.02 \\
\hline Composite outcome & $31 \%(21)$ & $29 \%(9)$ & $33 \%(12)$ & 0.71 \\
\hline
\end{tabular}

$\mathrm{AS}=$ Apgar score, IVH = intraventricular hemorrhage, BPD = bronchopulmonary dysplasia, ROP = retinopathy of prematurity, RBC = red blood cells, composite outcome = post discharge mortality, impaired neuromotor development, deafness or blindness

approached statistical significance in favor of the liberal group. A post-hoc analysis with cognitive delay redefined (MDI score more than 1SD below the age-standardized mean) showed a significant difference favoring the liberal threshold group. This suggests that premature infants may benefit from a higher hemoglobin threshold for transfusion [4]. In the study by Nopoulos et al. on the brain structure of 12 year old children previously enrolled in the Iowa trial by Bell and colleagues, only 44 of the 100 children participated [3]. The children who were exposed to the liberal transfusion threshold appeared to have a substantially smaller intracranial volume compared to the children transfused according to the restrictive guideline. Nopoulos mentions unpublished data on long-term cognitive follow-up showing (non-significant but) overall poorer outcome in the group of liberal transfused children.

Another recent study has shown that RBC transfusions increase cerebral oxygenation, thereby decreasing the risk of tissue hypoxia [26]. Mercer et al. showed that premature male infants after delayed cord clamping, had a better developmental outcome at seven months CA compared to infants after immediate cord clamping [27].

Table 2 Predictors of the composite outcome of neuromotor developmental delay, post-discharge mortality, blindness or deafness

\begin{tabular}{llll}
\hline & P-value & OR & Cl of OR (95\%) \\
\hline Hospital & 0.8 & 1.6 & $0.1-24.7$ \\
\hline Number of RBC transfusions & 1.0 & 1.0 & $0.2-4.8$ \\
\hline ML/kg RBC transfused & 1.0 & 1.0 & $0.9-1.1$ \\
\hline Gender & 0.2 & 0.4 & $0.0-1.6$ \\
\hline Gestational age & 0.8 & 1.0 & $0.9-1.1$ \\
\hline Birth weight & 0.4 & 1.0 & $1.0-1.0$ \\
\hline CRIB I| score & 0.6 & 1.0 & $1.0-1.0$ \\
\hline Apgar score 5 min & 0.3 & 1.2 & $0.8-1.9$ \\
\hline
\end{tabular}

$\mathrm{RBC}=$ red blood cells
It is conceivable that upon transfusion of a larger volume, an increase in cerebral flow and better oxygenation can be obtained with a similar effect as described by Mercer.

In transfusion guidelines, the range of recommended $\mathrm{RBC}$ volume per kilogram bodyweight is rather wide, $10-20 \mathrm{ml} / \mathrm{kg}$. Given the variation in hematocrit between used $\mathrm{RBC}$ products, the guidelines result in a huge variation in actually transfused RBC.

We observed no influence of transfused volume RBC per kg bodyweight on a composite of impaired neuromotor development, post discharge mortality and deafness or blindness in extremely preterm born infants evaluated at 24 months $\mathrm{CA}$. This finding remained unchanged after logistic regression analysis correcting for other factors relevant for outcome.

The two Dutch NICUs participating in this study used the same transfusion guideline, transfusion trigger and transfusion product, which virtually excludes important differences in degree of anemia between infants. Our study has its limits being a retrospective, non-randomized trial. The neuromotor development was assessed using various different tests. In Unit B all children were assessed by the same special educator who is also a pediatric physiotherapist (ICvH) using the same test (BSID-II-NL) in 95\% of the children. The children from Unit A were assessed using various validated tests, performed in different hospitals by different professionals. It may be an incentive to perform a larger, prospective randomized controlled trial, focusing not only on the transfusion trigger but also on the total transfused RBC volume to recommend an optimal transfusion trigger and dose.

\section{Conclusion}

A high total transfused volume of RBC per $\mathrm{kg}$ was not correlated with the composite outcome of impaired neuromotor developmental outcome, post discharge mortality, blindness or deafness when analyzed at $24 \pm 3.4$ 
months CA, hereby questioning the previously presumed possible detrimental effects of RBC transfusions.

\section{Recommendations}

Due to differences in neonatal transfusion practice, conclusions on the effect of maintaining a higher $\mathrm{Hb}$ value by the use of liberal transfusion triggers or a larger volume of $\mathrm{RBC}$ per transfusion are not based on strong evidence. A larger transfusion volume may not be associated with deleterious effects, whereas a smaller transfusion volume may limit donor exposure. Through randomized clinical studies, the effect of more liberal or restrictive triggers on long-term outcome can be studied, as well as the combination with a low $(10 \mathrm{ml} / \mathrm{kg})$ or high $(20 \mathrm{ml} / \mathrm{kg})$ transfusion volume. A longitudinal study to school age or even adolescence looking for instance at academic competencies might give further insight in the effects of different transfusion volumes.

\section{Acknowledgements}

We thank all neonatologists, especially dr Hens Brouwers, and pediatricians at the University hospitals of Utrecht and Leiden and their referral hospitals for their support in this study.

\section{Author details}

'Division of Neonatology J6-S, Department of Pediatrics, Leiden University Medical Center, PO BOX 9600, 2300RC Leiden, the Netherlands. 'Department of Pediatrics, Groene Hart Ziekenhuis, Gouda, the Netherlands. ${ }^{3}$ Sanquin Blood Bank South-West Region, Leiden, the Netherlands. ${ }^{4}$ Department of Obstetrics, University Medical Center Utrecht, Utrecht, the Netherlands. ${ }^{5}$ Department of Neonatology, Wilhelmina Children's Hospital, University Medical Center Utrecht, Utrecht, the Netherlands. 'Department of Immunohaematology and Transfusion, Leiden University Medical Center, Leiden, the Netherlands. 'Juliana Children's Hospital, the Hague, the Netherlands.

\section{Authors' contributions}

JSVL and CK made substantial contributions to the study design, data retrieval and analysis and interpretation of the data. Both were involved in writing and revising the manuscript.

$\mathrm{KEAH}, \mathrm{IcvH}, \mathrm{CKE}$ and PHTVZ made substantial contributions to the

acquisition of data and critical revision of the manuscript. $A B$ and FJW made substantial contributions to the study design and analysis and interpretation of the data and were involved in revising the manuscript for important intellectual content. All authors have given approval of the final document.

\section{Competing interests}

The authors declare that they have no competing interests.

Received: 23 August 2010 Accepted: 28 May 2011

Published: 28 May 2011

\section{References}

1. New HV, Stanworth SJ, Engelfriet CP, Reesink HW, McQuilten ZK, Savoia HF, Wood EM, Olyntho S, Trigo F, Wendel S, et al: Neonatal transfusions. Vox Sang 2009, 96:62-85.

2. Khodabux CM, Hack KE, von Lindern JS, Brouwers H, Walther FJ, Brand A: A comparative cohort study on transfusion practice and outcome in two Dutch tertiary neonatal centres. Transfus Med 2009, 19:195-201.

3. Nopoulos PC, Conrad AL, Bell EF, Strauss RG, Widness JA, Magnotta VA, Zimmerman MB, Georgieff MK, Lindgren SD, Richman LC: Long-term Outcome of Brain Structure in Premature Infants: Effects of Liberal vs Restricted Red Blood Cell Transfusions. Arch Pediatr Adolesc Med 2011, 165(5):443-50.
4. Whyte RK, Kirpalani H, Asztalos EV, Andersen C, Blajchman M, Heddle N, LaCorte M, Robertson CM, Clarke MC, Vincer MJ, et al:

Neurodevelopmental outcome of extremely low birth weight infants randomly assigned to restrictive or liberal hemoglobin thresholds for blood transfusion. Pediatrics 2009, 123:207-213.

5. Bell EF, Strauss RG, Widness JA, Mahoney LT, Mock DM, Seward VJ, Cress GA, Johnson KJ, Kromer IJ, Zimmerman MB: Randomized trial of liberal versus restrictive guidelines for red blood cell transfusion in preterm infants. Pediatrics 2005, 115:1685-1691.

6. Kirpalani H, Whyte RK, Andersen C, Asztalos EV, Heddle N, Blajchman MA, Peliowski A, Rios A, LaCorte M, Connelly R, et al: The Premature Infants in Need of Transfusion (PINT) study: a randomized, controlled trial of a restrictive (low) versus liberal (high) transfusion threshold for extremely low birth weight infants. J Pediatr 2006, 149:301-307.

7. Dutch Institute for Health and Improvement CBO Guideline Bloodtransfusion: Guideline Bloodtransfusion Alphen aan den Rijn; 2004

8. Bayley N: Manual for the Bayleys Scales of Infant Development San Antonio: The Psychological Corporation; 1995.

9. Griffiths R: The abilities of young children; a comprehensive system of mental measurement for the first eight years of life High Wycombe: The Test Agency, ARICD; 1984.

10. Piper MC, Darrah J: Motor assessment of the developing infant Philadelphia: Saunders; 1994.

11. Hempel MS: Neurological development during toddling age in normal children and children at risk of developmental disorders. Early Hum Dev 1993, 34:47-57.

12. Touwen BCL: Examination of the child with minor neurological dysfunction. 2 edition. Clinics in Developmental Medicine; 1979, 71.

13. Laurent de Angulo MS, Brouwers-de Jong EA, Bijlsma-Schlosser JFM, BulkBunschoten AMW, Pauwels JH, Steinbruch-Linstra I: Ontwikkelingsonderzoek in de jeugdgezondheidszorg Het Van Wiechenonderzoek - De Baecke-Fassaert Motoriektest Assen: Uitgeverij Van Gorcum; 2005.

14. Ehrenkranz RA, Walsh MC, Vohr BR, Jobe AH, Wright LL, Fanaroff AA, Wrage LA, Poole K: Validation of the National Institutes of Health consensus definition of bronchopulmonary dysplasia. Pediatrics 2005, 116:1353-1360.

15. The International Classification of Retinopathy of Prematurity revisited. Arch Ophthalmol 2005, 123:991-999.

16. Volpe Joseph J: Intracranial Hemorrhage: Germinal Matrix-Intraventricular Hemorrhage of the Premature Infant. Neurology of the Newborn. 5 edition. philadelphia: saunders elsevier; 2008, 517-588.

17. Akkoyun I, Oto S, Yilmaz G, Gurakan B, Tarcan A, Anuk D, Akgun S, Akova YA: Risk factors in the development of mild and severe retinopathy of prematurity. J AAPOS 2006, 10:449-453.

18. Brooks SE, Marcus DM, Gillis D, Pirie E, Johnson MH, Bhatia J: The effect of blood transfusion protocol on retinopathy of prematurity: A prospective, randomized study. Pediatrics 1999, 104:514-518.

19. Dani C, Reali MF, Bertini G, Martelli E, Pezzati M, Rubaltelli FF: The role of blood transfusions and iron intake on retinopathy of prematurity. Early Hum Dev 2001, 62:57-63.

20. Sacks LM, Schaffer DB, Anday EK, Peckham GJ, Delivoria-Papadopoulos M: Retrolental fibroplasia and blood transfusion in very low-birth-weight infants. Pediatrics 1981, 68:770-774.

21. Collard KJ: Is there a causal relationship between the receipt of blood transfusions and the development of chronic lung disease of prematurity? Med Hypotheses 2006, 66:355-364.

22. Cooke RW, Drury JA, Yoxall CW, James C: Blood transfusion and chronic lung disease in preterm infants. Eur J Pediatr 1997, 156:47-50.

23. Silvers KM, Gibson AT, Russell JM, Powers HJ: Antioxidant activity, packed cell transfusions, and outcome in premature infants. Arch Dis Child Fetal Neonatal Ed 1998, 78:F214-F219.

24. Chen HL, Tseng HI, Lu CC, Yang SN, Fan HC, Yang RC: Effect of blood transfusions on the outcome of very low body weight preterm infants under two different transfusion criteria. Pediatr Neonatol 2009, 50:110-116.

25. Hirano K, Morinobu T, Kim H, Hiroi M, Ban R, Ogawa S, Ogihara H, Tamai H, Ogihara T: Blood transfusion increases radical promoting non-transferrin bound iron in preterm infants. Arch Dis Child Fetal Neonatal Ed 2001, 84: F188-F193.

26. Dani C, Pratesi S, Fontanelli G, Barp J, Bertini G: Blood transfusions increase cerebral, splanchnic, and renal oxygenation in anemic preterm infants. Transfusion 2010, 50:1220-1226. 
27. Mercer JS, Vohr BR, Erickson-Owens DA, Padbury JF, Oh W: Seven-month developmental outcomes of very low birth weight infants enrolled in a randomized controlled trial of delayed versus immediate cord clamping. J Perinatol 2010, 30:11-16.

\section{Pre-publication history}

The pre-publication history for this paper can be accessed here: http://www.biomedcentral.com/1471-2431/11/48/prepub

doi:10.1186/1471-2431-11-48

Cite this article as: von Lindern et al:: Long-term outcome in

relationship to neonatal transfusion volume in extremely premature

infants: a comparative cohort study. BMC Pediatrics 2011 11:48.

Submit your next manuscript to BioMed Central and take full advantage of:

- Convenient online submission

- Thorough peer review

- No space constraints or color figure charges

- Immediate publication on acceptance

- Inclusion in PubMed, CAS, Scopus and Google Scholar

- Research which is freely available for redistribution

Submit your manuscript at www.biomedcentral.com/submit 